\title{
Characterization of Neurons of the Supramammillary Nucleus and Mammillary Body That Discharge Rhythmically with the Hippocampal Theta Rhythm in the Rat
}

\author{
Bernat Kocsis and Robert P. Vertes \\ Center for Complex Systems, Florida Atlantic University, Boca Raton, Florida 33431
}

We examined the activity of single cells of the supramammillary nucleus (SUM), the mammillary body (MB), and adjacent regions of the diencephalon with respect to the hippocampal electroencephalogram (EEG) in urethaneanesthetized rats. Twenty-nine of 170 cells were found to discharge synchronously with the theta rhythm of the hippocampus (theta-related neurons). All of the 29 theta-related cells were localized to the SUM or MB. A subset of thetarelated cells of SUM and MB discharged in short-duration bursts comparable to the pyramidal complex spike cells of the hippocampus. In contrast to hippocampal complex spikes, however, which predominantly exhibit this mode of firing during non-theta states, the burst firing of SUM/MB cells was strongly correlated with the theta rhythm. The proportion of bursting neurons was higher in MB than in SUM. Using partial coherence analysis, we examined the relationship between SUM/MB theta-related cells and the two generators of theta of the dorsal hippocampus. The theta-related cells of MB showed a stronger correlation with "CA1" than with "dentate" theta, whereas no such asymmetry was found in the relationship between neuronal firing of SUM cells and the two generators of theta in the hippocampus. The foregoing suggests that the theta-related cells of $\mathrm{MB}$ are driven by descending projections from the hippocampal formation (CA1), whereas those of the SUM are not. The SUM and MB are intimately connected with the hippocampal formationthe SUM mainly via ascending projections to the dentate gyrus, and the MB via direct descending projections from the subiculum. Theta-related SUM/MB cells may be directly involved in the generation of theta and/or the transfer of theta rhythmicity to various parts of the limbic system and forebrain.

[Key words: hippocampal theta rhythm, supramammillary nucleus, mammillary body, bursting units, complex spikes, coherence analysis]

A prominent feature of the hippocampal EEG is the rhythmic slow activity (theta rhythm) that can be recorded as a largeamplitude, nearly sinusoidal oscillation of the field potential (Jung and Kornmuller, 1938; Green and Arduini, 1954). The

\footnotetext{
Received Dec. 27, 1993; revised May 16, 1994; accepted May 19, 1994.

We thank Drs. J. A. S. Kelso and I. Soltese for their critical reading of the manuscript. This work was supported by NIMH Grant MH45075 to R.P.V

Correspondence should be addressed to Bernat Kocsis, Department of Physiology, National Institute of Ncurosurgery, H-1145 Budapest, Hungary.

Copyright (c) 1994 Society for Neuroscience $0270-6474 / 94 / 147040-13 \$ 05.00 / 0$
}

hippocampal theta rhythm has attracted considerable interest because of its relation to behavior and possible involvement in mnemonic processes. In the rat, theta rhythm is present during behavioral states associated with learning and memory, namely, exploration and rapid eye movement sleep (Vanderwolf, 1969; Winson, 1972). Several reports have shown (Larson and Lynch, 1986; Rose and Dunwiddie, 1986; Staubli and Lynch, 1987; Greenstein et al., 1988) that stimulation in the theta frequency range $(5 \mathrm{~Hz})$ is optimal for the induction of long-term synaptic potentiation (LTP), a candidate cellular mechanism of memory storage. During naturally occurring theta, LTP is enhanced in DG by theta-rhythmic stimulation when delivered in-phase with the synchronous high-frequency discharge of the granule cells (Pavlides et al., 1988).

The medial septum/vertical limb of the diagonal band nucleus (MS/vDB) (Petsche et al., 1962) as well as the lateral and medial entorhinal cortices (Ranck, 1973) contain rhythmically firing cells directly involved in the generation of the hippocampal theta rhythm. The MS/vDB appears to serve as the ultimate "pacemaker" that entrains all other theta elements in the hippocampus and the entorhinal cortex (Bland, 1986; Vertes, 1986; Stewart and Fox, 1990). The septal pacemaker is thought to convert the steady, nonrhythmic flow of pulses from the reticular formation into theta-rhythmic activity (Petsche et al., 1965). In support of this it has been demonstrated (1) that theta can be elicited by high-frequency stimulation of the reticular formation (Green and Arduini, 1954; Petsche et al., 1962; Stumpf et al., 1962), most effectively in the nucleus pontis oralis (RPO) (Vertes, 1981); (2) that during theta-associated behaviors, a large percentage of RPO neurons increase their firing rates but show no rhythmical activity (Vertes, 1979; Nunez et al., 1991); and (3) that MS/vDB lesions abolish hippocampal theta elicited with brainstem stimulation (Green and Arduini, 1954).

Anatomical studies have shown that RPO does not project directly to the MS/vDB (Vertes, 1984, 1988; Vertes and Martin, 1988), but indirectly through a multisynaptic network. It has been proposed that the supramammillary nuclcus (SUM) of the hypothalamus may be an important relay mediating brainstem influences on the septum-hippocampal formation (Vertes, 1986) in the generation of theta. Regarding the latter, the RPO projects to the SUM (Vertes and Martin, 1988) and the SUM, in turn, is the source of pronounced projections to the medial and lateral septum (Shepard et al., 1988; Vertes, 1988, 1992), the hippocampus (mainly DG) (Wyss et al., 1979; Dent et al., 1983; Haglund et al., 1984; Saper, 1985; Vertes, 1992; Magloczky et al., in press), and the entorhinal cortex (Room and Groenewegen, 1986; Vertes, 1992). 
Kirk and McNaughton (1991) described a population of SUM cells (multiunit recordings) in the urethane-anesthetized rat that discharge synchronously with the theta rhythm. Procaine injections into the medial septum that abolished theta in the hippocampus did not alter the rhythmical firing of these SUM neurons. Oddie et al. (in press), also using urethane-anesthetized rats, recently demonstrated that hippocampal theta elicited with RPO stimulation was reversibly blocked by procaine injections in the posterior hypothalamus/SUM region.

The mammillary body (MB), like the SUM, is intimately connected with the septum-hippocampus and possibly with the SUM (Swanson and Cowan, 1975, 1977, 1979; Shibata, 1988; Gonzalo-Ruiz et al., 1992). It is well recognized that the mammillary body constitutes a key element of Papez's circuit (Papez, 1937; MacLean, 1952); that is, the MB is an integral part of the loop in which signals are relayed from the septum (Swanson and Cowan, 1979; Gonzalo-Ruiz et al., 1992), subiculum (Swanson and Cowan, 1975, 1977) and entorhinal cortex (Shibata, 1988) to MB and from there back to the hippocampus/entorhinal cortex via the anterior nuclei of the thalamus. It has been demonstrated in an in vitro study, that neurons in the mammillary body (MB) have the ability to generate (medial nucleus of $\mathrm{MB}$ ) and/or follow (medial or lateral nuclei of MB) rhythmic discharge in the theta frequency range (Alonso and Llinas, 1992; Llinas and Alonso, 1992).

The SUM/MB, then, would appear to occupy a strategic position in the crossroads of ascending and descending traffic between the brainstem and the limbic forebrain (septum-hippocampus) possibly involved in triggering and/or enhancing theta rhythmical activity.

In the present study, we systematically examined the discharge properties of cells of the posterior hypothalamus of the urethane-anesthetized rat with respect to the hippocampal EEG. The main objectives of the study were (1) to examine the distribution of cells in caudal diencephalic structures exhibiting theta-related activity; (2) to quantify the strength of relationship between posterior hypothalamic theta-related cells and the hippocampal EEG using coherence spectral analysis; (3) to analyze the discharge characteristics of MB cells relative to their membrane properties described in vitro (Alonso and Llinas, 1992; Llinas and Alonso, 1992), that is, to examine whether the bursting activity described in vitro is present in vivo and whether it is entrained to hippocampal theta; and (4) to analyze the direction of influence between SUM/MB and the hippocampus, using partial coherence analysis.

\section{Materials and Methods}

\section{Unit/EEG recordings}

The experiments were performed on 40 male Sprague-Dawley rats weighing 250-325 gm. Under methoxyflurane (Metofane, Pitman-Moore) anesthesia, each rat was implanted with a jugular catheter for the subsequent delivery of urethane anesthesia. The rats were maintained on urethane anesthesia for the duration of the experiment. Under urethane, rats were implanted with a bipolar electrode [a pair of Teflon-coated stainless steel wires $(125 \mu \mathrm{m})$ separated by $0.75-1.0 \mathrm{~mm}$ at their tips] on the right side of the dorsal hippocampus (AP $-3.7 \mathrm{~mm}$ caudal to bregma, Lat $2.2 \mathrm{~mm}$ ) to record the hippocampal EEG. The electrode was lowered to a depth of $3.5-4.0 \mathrm{~mm}$ below the surface of the skull and positioned to record the EEG from the two out-of-phase theta oscillators of the dorsal hippocampus (Winson, 1974; Bland et al., 1975). The electrode was then fixed to the skull with dental cement. The EEG signals were recorded with bandpass settings of $3 \mathrm{IIz}$ to $75 \mathrm{IIz}$ or 100 $\mathrm{Hz}$. A region of the skull overlying the caudal diencephalon (i.e., region of the supramammillary nucleus) was removed to allow for the insertion of unit microelectrodes. Units were recorded with glass microelectrodes (4-6 $\mathrm{M} \Omega$ ) filled with $0.5 \mathrm{M}$ sodium acetate and $2 \%$ pontamine sky blue. The unit recording was filtered between $300 \mathrm{~Hz}$ and $10 \mathrm{kHz}$. All signals were stored on magnetic tape and analyzed off line.

\section{Data analysis}

Preprocessing. Analog-to-digital conversion was performed with 12 bit resolution at two different sampling rates (using the ISC-16 A/D card and EGAA software, RC Electronics). (1) The spike train from single cell recordings with high signal-to-noise ratio was processed with a slope/ height window discriminator (Frederick Haer) and together with the other signals was sampled at $250 \mathrm{~Hz}$. (2) For separation of spikes in multiunit extracellular recordings or in noisy recordings, the signals were sampled with sampling periods between 30 and $60 \mu$. Spike separation was performed using the $\mathrm{K}$-means clustering algorithm of Hartigan (1975) modified for application to spontaneously occurring waveforms (Dembowsky et al., 1988; Kocsis et al., 1989). The spikes were represented as points in a 10-dimensional feature space using 10 voltage samples that had the highest variance (Salganicoff et al., 1988). The dissimilarity of the waveforms was measured as the Euclidean distance between the corresponding points in this space. The classification procedure was run separately for different numbers of clusters $(2-10)$. In each case, the K-means algorithm performed an iterative search for an optimal partition, first transferring objects from one cluster to another and then updating the cluster centers. The proper number of clusters was determined on the basis of two statistical variables that allowed for an analysis of the change in the ratio between the average variance within clusters and the distances between the cluster centers. The clusters were formed by waveforms closely resembling each other and some of them contained spikes of separate neurons. In an interactive section, the clusters were reviewed and adjusted and those with identified spikes were selected. Their "centers" were used as templates for further analyses. A certain cluster was considered to represent a single neuron, if the counts in the first $2 \mathrm{msec}$ of the autocorrelation function (i.e., corresponding to the absolute refractory period) was less then $5 \%$ of the maximum number of counts in the histogram (Christakos et al., 1991).

Time domain analysis. Time domain analysis was used to verify that the spikes were obtained from a single neuron, and also to examine rhythmical neuronal discharge and correlation between single unit firing and hippocampal field potentials at the dominant frequency. The interspike interval histograms (ISIHs) were calculated after the spike train was converted at high sampling rate and single cells were carefully identified. The autocorrelograms and unit-EEG cross-correlograms were either calculated from the raw spike train or from its representation by a series of standard pulses sampled at lower rate. The first provides higher resolution and allows for a more precise spike separation, while the latter makes it possible to run the analysis on a longer time segment.

Frequency domain analysis. Frequency domain analysis was performed using a customized program for spectral analysis (Kocsis et al., 1990). Before digital sampling (at $250 \mathrm{~Hz}$ ), the hippocampal EEG was subjected to bandpass filtering $(1-75 \mathrm{~Hz})$ and the unit's spike train was processed with a voltage/time window discriminator. Autospectra and coherence functions relating single unit activity to the hippocampal EEG were computed using the algorithm of Christakos and coworkers (1991; see also Leung and Buzsaki, 1983). For unit spikes, digital low-pass filtering was performed by convolving the sequence of standardized pulses representing spike trains with a sinc function (defined as $\sin x / x$ ) having set the parameters so that the information in the autospectrum reflected the interspike intervals rather than the shape of the standardized pulses. The fast Fourier transform was performed on contiguous windows that were $4 \mathrm{sec}$ in duration. The raw spectra, smoothed with a three point moving average, were averaged over the windows to obtain the final auto- and cross-spectra, and from these spectra the coherence functions were computed. The $95 \%$ confidence value, which strongly depends on the number of windows averaged, was calculated to test the significance of the coherence estimates. Similar analyses have been used in the detection and quantification of rhythmical activity of brainstem neurons related to a number of physiologically relevant events [e.g., respiratory (Christakos et al., 1991), circulatory (Gebber et al., 1990), or theta EEG (Leung and Buzsaki, 1983; Kocsis and Vertes, 1992)], even if there were coexisting rhythms or the rhythm of interest was more a modulation of a neuron's discharge rather than its basic firing frequency. In those experiments in which coherence spectral analysis involved three sets of rhythmical signals (e.g., two EEG recordings and 


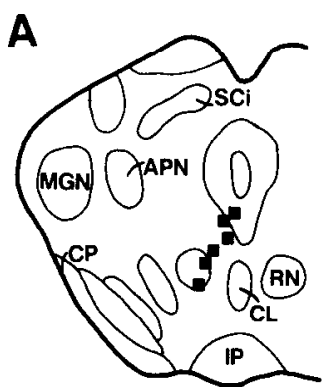

$\mathbf{E}$

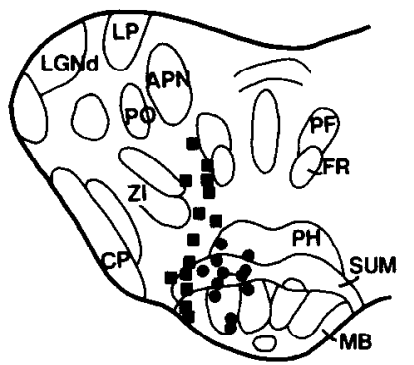

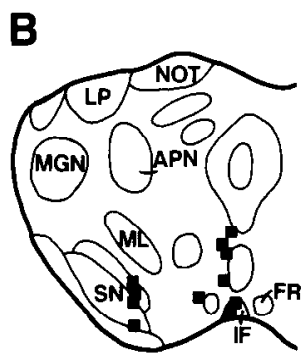

$\mathbf{F}$

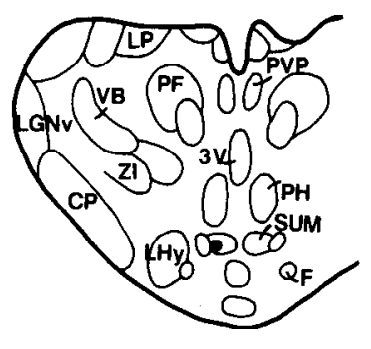

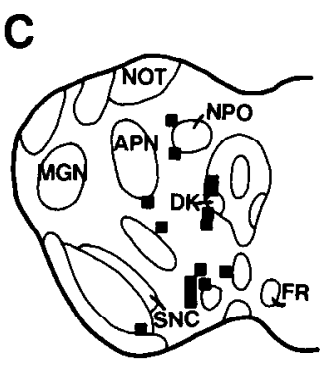

G

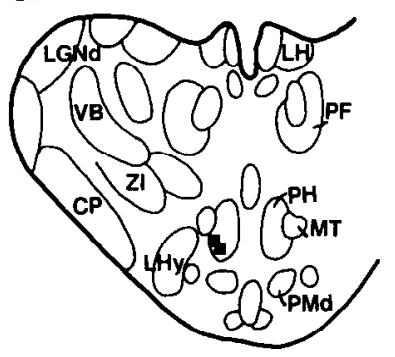

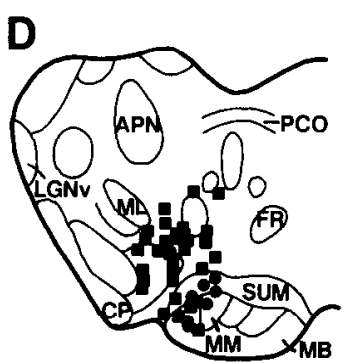

H

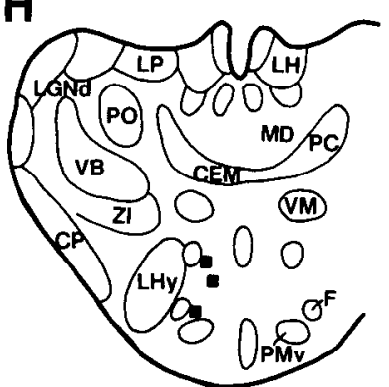

Figure 1. Series of schematic transverse sections through the rostral midbrain-caudal diencephalon $(A-H)$ depicting the locations of histologically identified theta-related (circles) and non-theta (squares) cells. $A P N$, anterior pretectal nucleus; $C L$, caudal linear nucleus; $C E M$, central medial nucleus of thalamus; $C P$, cerebral peduncle; $D K$, nucleus of Darkschewitsch; $F$, fornix; $F R$, fasciculus retroflexus; $I F$, interfascicular nucleus; $I P$, interpeduncular nucleus; $L G N d$, v, lateral geniculate nucleus, dorsal, ventral divisions; $L H$, lateral habenula; $L H y$, lateral hypothalamus; $L P$, lateral posterior nucleus of thalamus; $M B$, mammillary body; $M D$, mediodorsal nucleus of thalamus; $M G N$, medial geniculate nucleus; $M L$, medial lemniscus; $M M$, medial mammillary nucleus; $M T$, mammillothalamic tract; $N O T$, nucleus of optic tract; $N P O$, nucleus of posterior commissure; $P C$, paracentral nucleus of thalamus; $P C O$, posterior commissure; $P F$, parafascicular nucleus; $P M d, v$, premammillary nucleus, dorsal, ventral divisions; $P H$, posterior hypothalamus; $P O$, posterior nucleus of thalamus; $P V P$, posterior paraventricular nucleus of thalamus; $R N$, red nucleus; $S C i$, superior colliculus, intermediate gray; $S N$, substantia nigra; $S N C$, substantia nigra, pars compacta; $S U M$, supramammillary nucleus; $V B$, ventrobasal complex of thalamus; $V M$, ventromedial nucleus of thalamus; $Z I$, zona incerta; $3 V$, third ventricle

the simultaneously recorded unit discharge), both the ordinary and partial coherence spectra were calculated using the algorithms of Jenkins and Watts (1968). Differences between corresponding ordinary and partial coherence values were statistically evaluated using the Student's $t$ test. Prior to statistical testing, peak coherence values were subjected to Fisher's $z$-transformation to obtain estimates with an approximately normal distribution (Lopes da Silva et al., 1980).

Coherence spectral analysis provides the following information. The ordinary coherence between two signals measures the linear correlation between these signals. It is bounded by zero and unity. The coherence value at any given frequency will be unity if there is a perfect linear correlation between the two signals. On the opposite end, the coherence value will be zero if the two signals are unrelated or nonlinearities predominate in their relationship. High coherence between EEG and unit discharge indicates that part of the unit autospectrum can be predicted from the variations of the EEG signal. When two EEG recordings are highly correlated, unit-EEG coherences will be similar for each of two EEGs due to components common to all three signals (Gersch and Goddard, 1970; Lopes da Silva et al., 1980). These components can be eliminated by partialization of the unit-EEG coherence using the other EEG signal (i.e., partial coherence). Thus, partial coherence allows a comparison of the correlation between the unit discharge and each of the EEGs.

\section{Histology}

Following completion of the experiment, rats were perfused intracardially under deep urethane anesthesia, their brains removed, stored in $10 \%$ formalin, and then sectioned at $60 \mu \mathrm{m}$ with a freezing microtome, generally $24-48 \mathrm{hr}$ after removal. Sections were stained with cresyl violet. The tips of the hippocampal recording electrodes were localized using the Prussian blue technique, while tips of the microelectrodes were localized by passing $50 \mu \mathrm{A}$ of current for $10 \mathrm{~min}(5 \mathrm{~min}$ cathodal, 5 min anodal), which generally produced an intense blue spot (pontamine sky blue) $100-200 \mu \mathrm{m}$ in diameter.

\section{Results}

Twenty-nine theta-related cells were recorded in 19 rats. Electrode locations were verified with pontamine sky blue for 20 of the 29 theta-related cells (13 in the SUM and 7 in the MB) or in 14 of 19 rats (Fig. 1). In five rats, the precise location of recorded cells in the SUM/MB could not be histologically determined. Indirect evidence (i.e., electrode position relative to skull coordinates, depth of recording, and location of electrode tract) indicated, however, that the remaining nine theta-related units were located in the mammillary/supramammillary complex. The SUM/MB recordings were biased toward theta-related cells and as such no analysis of relative percentages of theta versus non-theta-related cells in this region is provided.

A total of 141 neurons ( 83 histologically verified; see Fig. 1) were non-theta cells. None of the cells histologically localized to regions of the diencephalon surrounding the SUM/MB but outside it (Fig. 1) fired synchronously with the hippocampal theta rhythm.

\section{Theta-related discharge of $S U M / M B$ cells}

Figures 2 and 4 characterize the discharge properties of thetarelated cells of the SUM in two rats; Figure 3 characterizes the discharge properties of an $\mathrm{MB}$ cell in a third rat. Figure 2 demonstrates the most common properties of theta-related cells found in SUM (Fig. 2) or in MB. The mean firing rate of the cell depicted in this figure was 13.4 spikes/sec during control conditions, that is, when no sensory stimulation was applied and when the hippocampal EEG was characterized by large-amplitude irregular activity. On sensory stimulation (5-10 sec tail 
$\mathbf{A}$

tail pinch

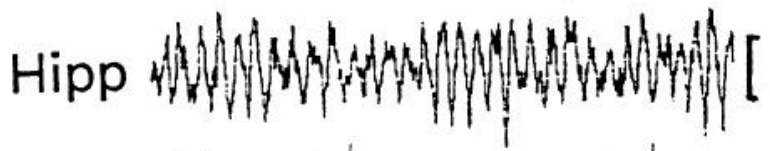

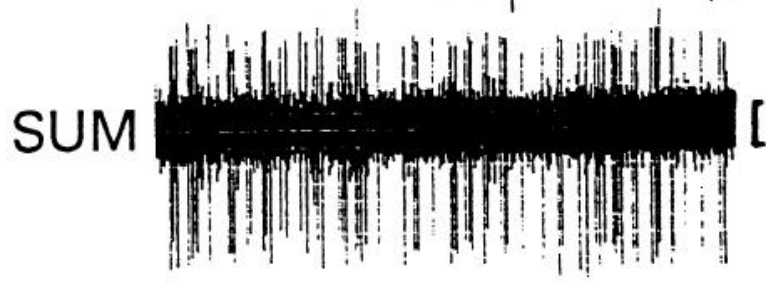

tail pinch

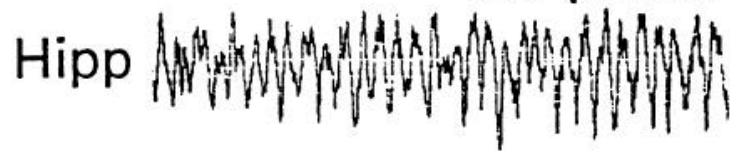
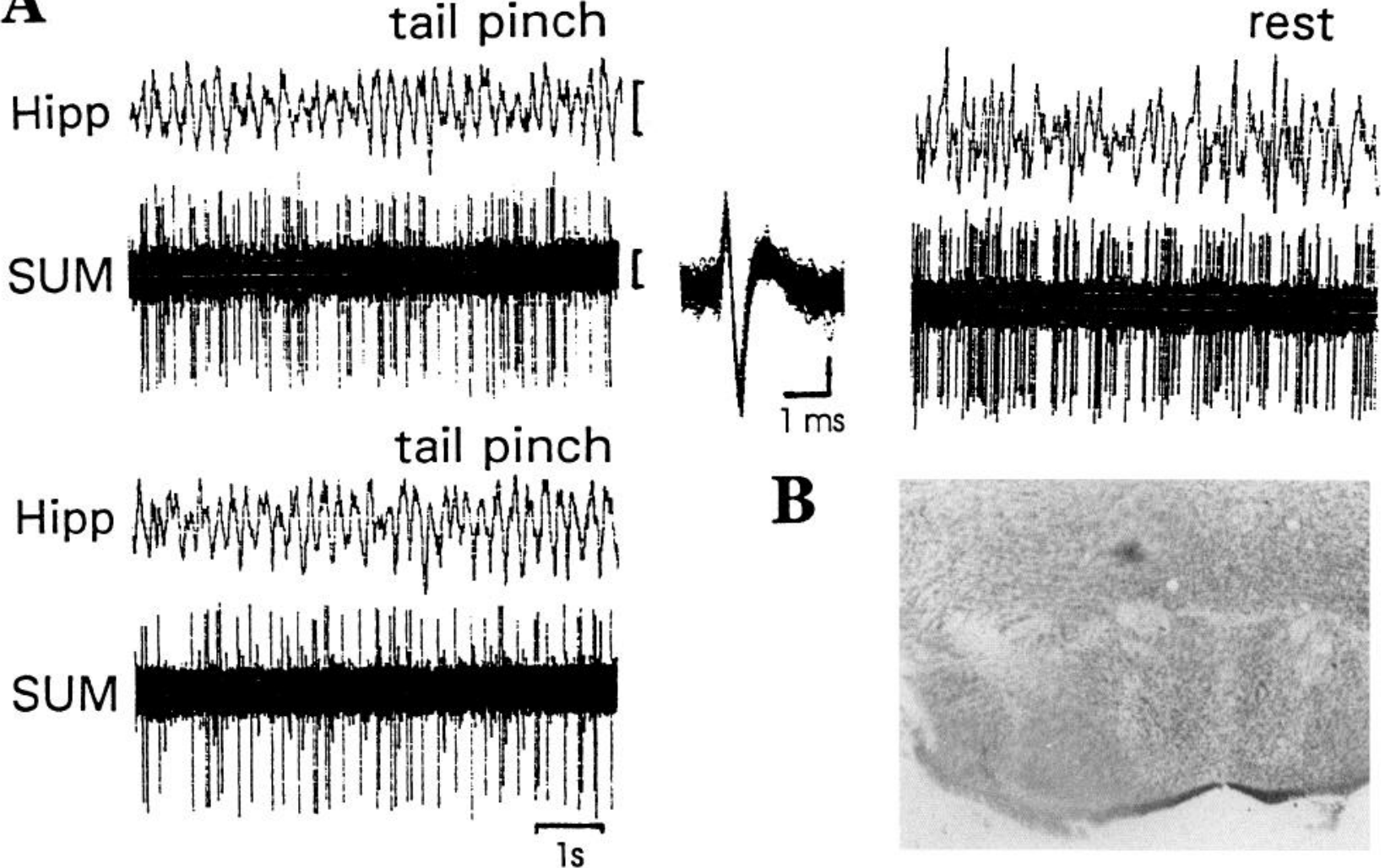

B

C

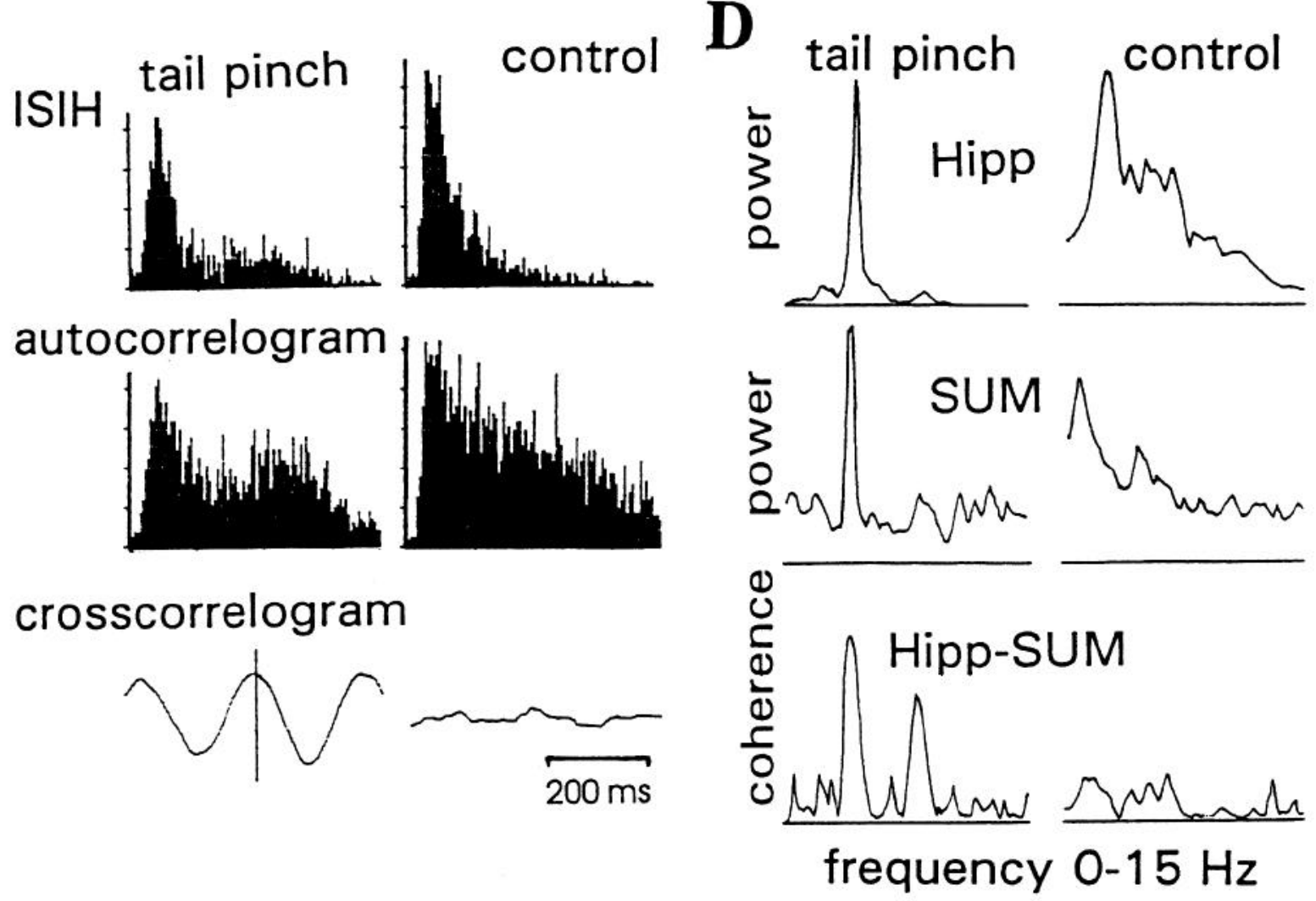

Figure 2. Characteristics of an SUM theta-cell. $A$, samples of rhythmic (after tail pinch) and irregular (at rest) electroencephalographic activity of the hippocampus (Hipp, top traces) and simultaneous unit discharge of an SUM cell (bottom traces). Inset shows superimposed extracellular potentials of the SUM unit. $B$, location of the neuron in the SUM. $C$, Time domain analysis of the SUM unit discharge (ISIH, interspike interval histogram, autocorrelogram) and its relationship to the hippocampal EEG (crosscorrelogram, spike-triggered average). $D$, spectral characteristics of the hippocampal EEG (top traces), SUM unit discharge (middle traces), and their relationship (bottom traces). Calibration: $A, 0.5 \mathrm{mV}$ (Hipp), $100 \mu \mathrm{V}(S U M) ;$ inset, $100 \mu \mathrm{V}$. 
pinch), the hippocampal EEG changed from an irregular pattern to rhythmic theta oscillations $(3-5 \mathrm{~Hz})$, and unit discharge became dominated by rhythmically occurring single spikes or shortduration bursts. The number of spikes in each burst was not stable and hence firing rate showed some variation between 8 and 12 spikes/sec (compare, e.g., top and bottom traces in Fig. $2 A$ ). The average (11.9 spikes/sec) was slightly lower than the firing rate during resting conditions. Interspike intervals within bursts were about $37 \mathrm{msec}(16-70 \mathrm{msec})$ as reflected in the dominant peak in the ISIH (Fig. 2C). A similar peak in the ISIH was observed during control conditions (non-theta) indicating similar interspike intervals for the two states.

An examination of rhythmical components of the unit's discharge showed that, in association with sensory evoked hippocampal theta, the cell fired rhythmically in synchrony with the hippocampal EEG. Following tail pinch, the originally unimodal autocorrelogram became bimodal with the second peak corresponding to theta frequency (Fig. $2 C$, middle traces). In the frequency domain, the irregular activity during resting conditions resulted in relatively broad-band autospectra for both SUM unit activity and the hippocampal EEG. Following sensory stimulation, however, the power in both signals was concentrated in a narrow band, characterized by the prominent peaks in the autospectra at $4.4 \mathrm{~Hz}$ (Fig. $2 \mathrm{D}$, top and middle traces).

The relationship between the two signals was examined using the spike-triggered average and coherence function. The spike triggered average shows hippocampal activity that preceded and followed the unit discharge at zero lag (Fig. $2 C$, bottom traces). Note that SUM unit activity was correlated with the rhythmic theta component of the hippocampal EEG during sensory stimulation but not during resting conditions. Accordingly, the coherence function describing the relationship between the two signals after tail pinch contained a high (0.87) narrow peak at theta frequency and a smaller one at its first harmonic whereas no significant coherence was found at any frequency during resting conditions (Fig. $2 D$, bottom traces).

The basic properties of the MB neuron shown in Figure 3 were similar to those of the SUM cell described above. This cell was located in the lateral nucleus of the MB (Fig. $3 B$ ), and fired at a rate of 5.6 spikes/sec-the lowest rate of any neuron of the SUM/MB sample. Theta-related discharge was evident from the raw recordings (Fig. $3 A$ ) and could be readily demonstrated in both the time (Fig. $3 C$ ) and frequency domains (Fig. 3D). There was, however, one significant difference between this lateral MB cell and the SUM cell of Figure 2. Under resting conditions, not only was the mean discharge rate of the MB cell within the theta frequency range, but it apparently fired quasirhythmical bursts at this frequency. This was reflected in the unit's autospectrum, which displayed a peak at $3.9 \mathrm{~Hz}$. The power in the spectrum, however, was not concentrated; rather, it was broadly distributed between 0 and $12 \mathrm{~Hz}$. Furthermore, although the autospectral maxima coincided in the MB and hippocampal recordings during resting, the two processes were not related (no coherence; Fig. $3 D$, bottom trace). In contrast, after tail pinch the peaks in both autospectra became narrow at $2.4 \mathrm{~Hz}$ and a high peak appeared in the coherence function at that frequency.

Spikes from single neurons, as demonstrated in Figures 2 and 3 , were positively isolated in 14 of 29 recordings. This was evident either from the very low variation in the shape of the spike (see, e.g., superimposed plots in Figs. $2 A$ and $3 A$ ), or determined on the basis of statistical calculations provided by the clustering program (see Materials and Methods). As further evidence of successful spike separation in these recordings, the first bins $(2-3 \mathrm{msec})$ of the autocorrelograms and ISIHs were empty or contained relatively low counts of spikes (Figs. $2 C$, $3 A, C)$.

In seven experiments, however, it was necessary to accept certain limitations in the accuracy of cell identification as the result of a low signal-to-noise ratio of the recording. An example of waveform clustering from noisy recording is shown in Figure 4. Three different classes of waveforms were identified (Fig. 4B). Two of them consisted of bipolar positive-negative spikes with differing amplitudes, and the third contained small negativepositive spikes. Note also that amplitudes of classes $b$ and $c$ were similar. Examination of autocorrelograms and cross-correlograms between each of these classes of spike trains suggests the following interpretation. Class $a$ contained spikes from a single cell (note empty bins in Fig. $4 D a$ ). Due to a degree of instability in the recording, however, a number of spikes, probably generated by a single neuron, had a lower amplitude and cntercd class $b$ (notc cmpty bins in the cross-correlogram in Fig. $4 F, a b$ ). Finally, small bipolar waves were differentiated from the background noise and divided into two groups of positivenegative (added to class $b$ ) and negative-positive waves (class $c$ ). Cross-correlograms between these various spike trains and the hippocampal EEG (Fig. $4 E$ ) showed that spikes $a$ and $b$ occurred in synchrony with hippocampal theta waves with similar phase delays. The correlation with theta was stronger, however, for $a$ than for $b$. In cases such as these, for the analysis (unit to slow-wave) we only used the "clean" classes (i.e., class $a$ in Fig. 4). This involved accepting the risk of underestimating the firing rate rather than compromising the estimate of the correlation by including spikes that did not belong to the same (class $a$ ) neuron.

Finally, for eight recordings the clustering failed to give reliable separation and consequently these recordings were considered to reflect multiunit activity.

Theta cells of the SUM/MB formed a rather homogeneous group in terms of spike shape, firing rate, and response to sensory stimulation. All neurons had positive-negative spikes, sometimes with an additional small and wide positive deflection at the end of the spike (see Fig. 3). The duration of spikes was 0.7$1.8 \mathrm{msec}$. The average firing rate of 29 cells was 14.2 spikes/ $\mathrm{sec}$, with a relatively small SD $( \pm 5.66)$. The range of firing rates was 5.6-26.9 spikes/sec. Fifteen of the 29 neurons $(>50 \%)$ fired at rates between 8.5 and 14 spikes/sec. The coherence between unit activity and hippocampal EEG at theta frequency was between 0.41 and 0.93 and averaged 0.66 . Since most neurons fired at rates several times higher than theta frequency $(2.8-4.4$ $\mathrm{Hz}$ ), the average number of spikes per cycle was usually between 2 and 8 . The number of spikes, however, changed from cycle to cycle. Slow cells occasionally missed firing during one or two consecutive cycles (e.g., Fig. 3). No differences in firing rate or coherence with theta were found for various recording sites in SUM/MB. There were, however, two important differences in the discharge of cells of the sample: (1) the ability of some neurons to fire in bursts, and (2) asymmetrical versus symmetrical relationships between a neuron's firing and the two hippocampal theta generators.

\section{Complex-spike cells in the $S U M / M B$}

Usually, when the activity of a neuron switched from irregular firing to theta rhythmicity, its discharge became periodically 
A

\section{rest}

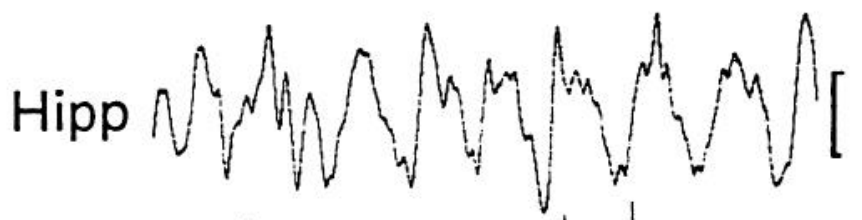

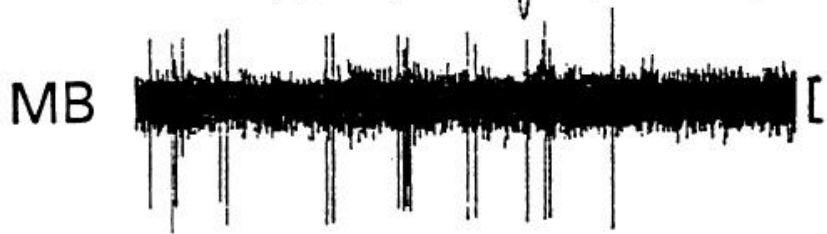

tail pinch

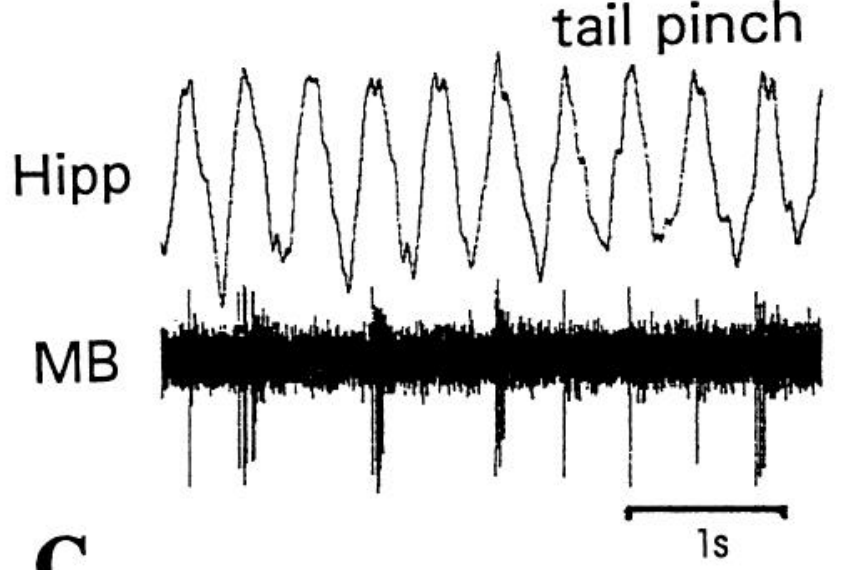

tail pinch

\section{autocorrelogram}

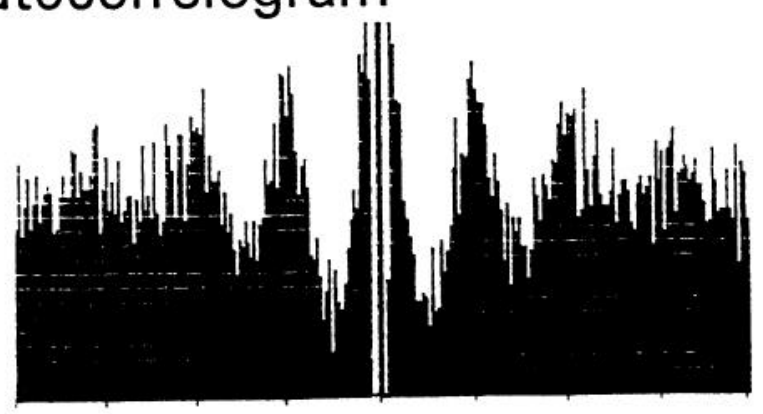

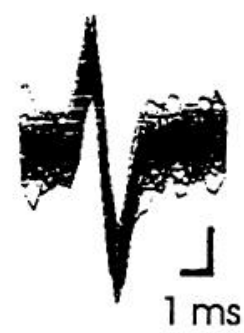

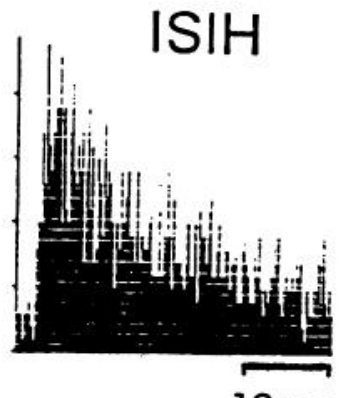

$10 \mathrm{~ms}$
D

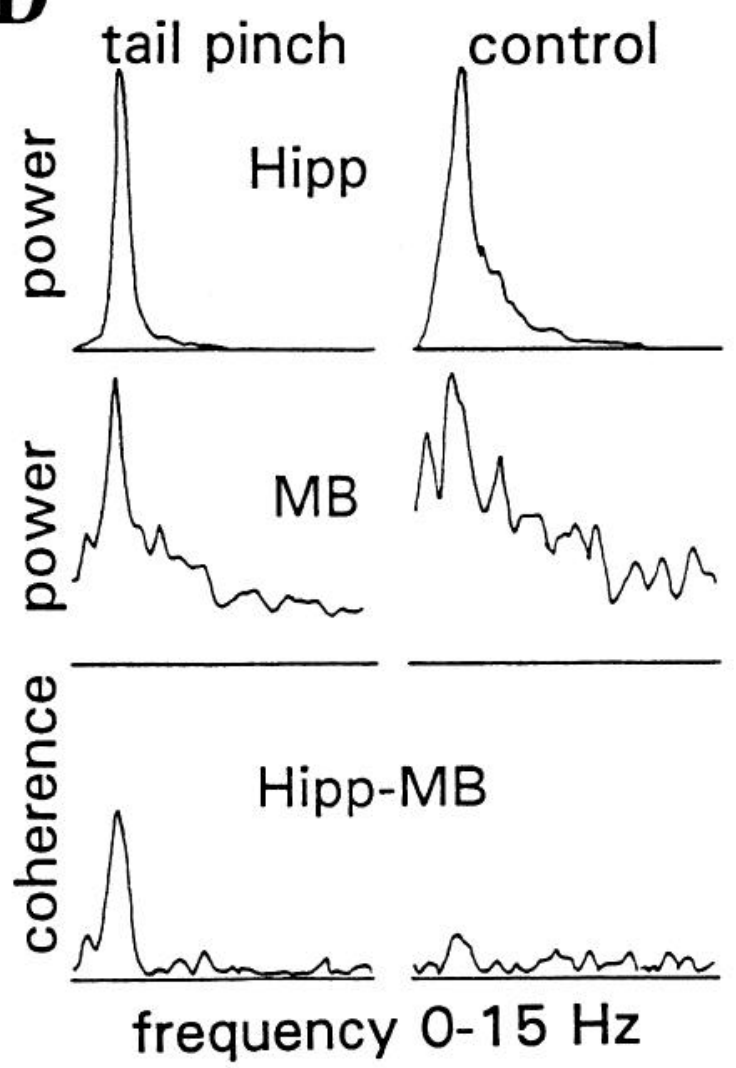

Figure 3. Characteristics of an MB theta-cell. A, Samples of electroencephalographic activity of the hippocampus (Hipp, top traces) and simultaneous unit discharge of an MB cell (bottom traces) at rest and after tail pinch. Inset, Superimposed extracellular potentials of the MB unit. ISIH, Interspike interval histogram of $\mathrm{MB}$ cell at rest. $B$, Location of the neuron in the MB. $C$, Time domain analysis of theta rhythmic discharge of the MB unit (autocorrelogram) and its relationship to the hippocampal EEG (crosscorrelogram, spike triggered average) after tail pinch. Correlograms depicted in two directions. $D$, Spectral characteristics of the hippocampal EEG (top traces), the MB unit discharge (middle traces), and their relationship (bottom traces). Calibration: A, $0.5 \mathrm{mV}$ (Hipp), $100 \mu \mathrm{V}(\mathrm{MB})$; inset, $100 \mu \mathrm{V}$. 

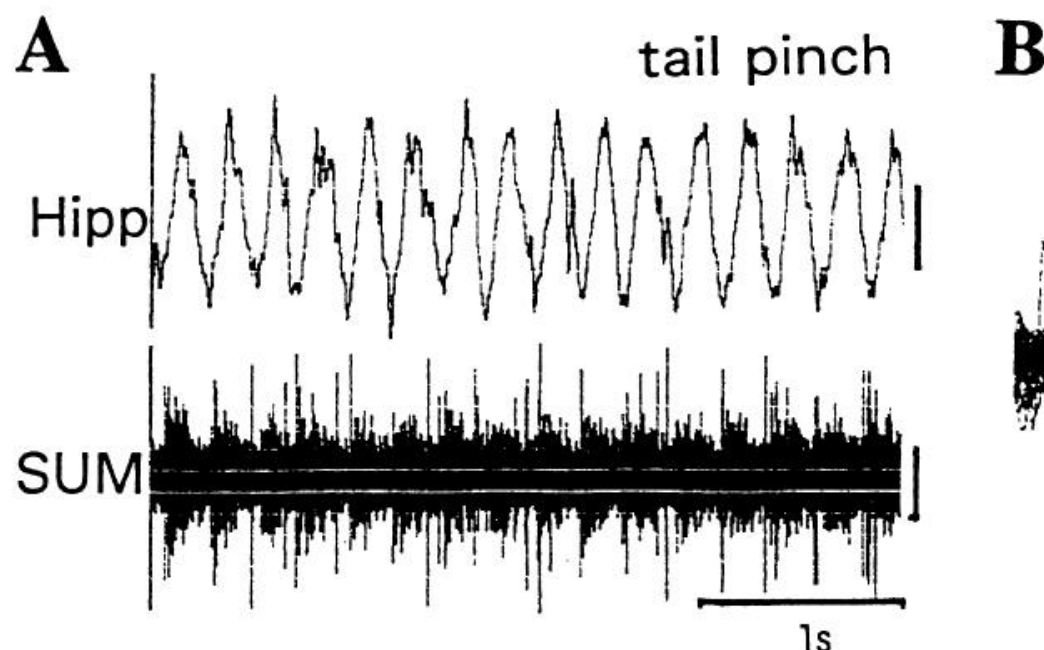

D

autocorrelogram

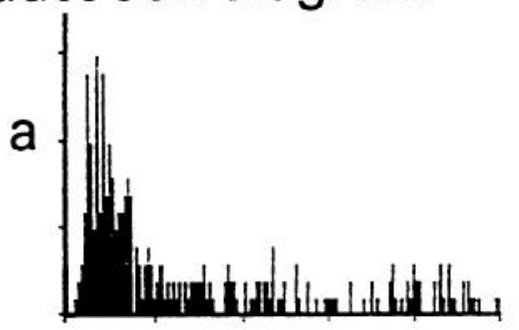

E Hipp-SUM crosscorr.

a

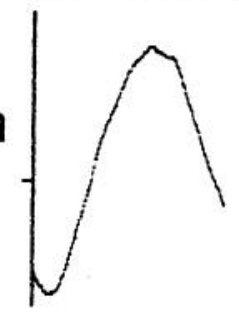

b

b
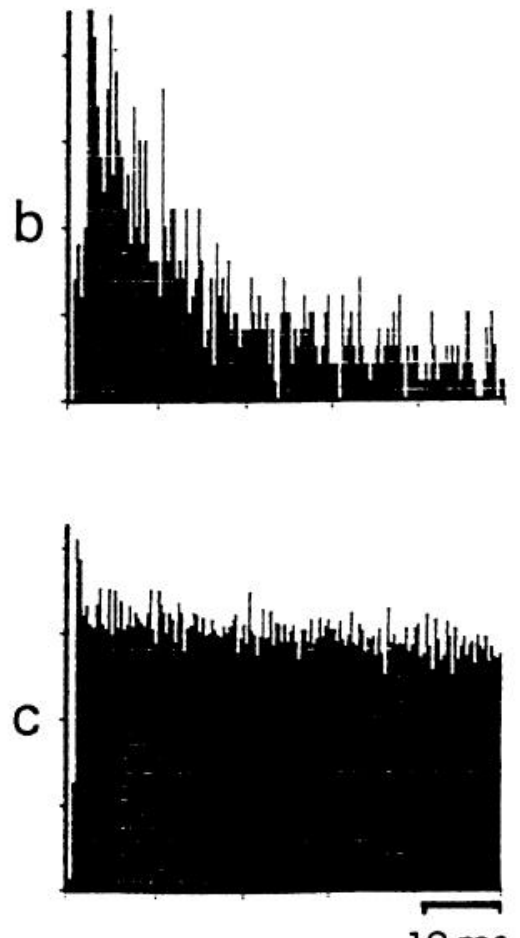
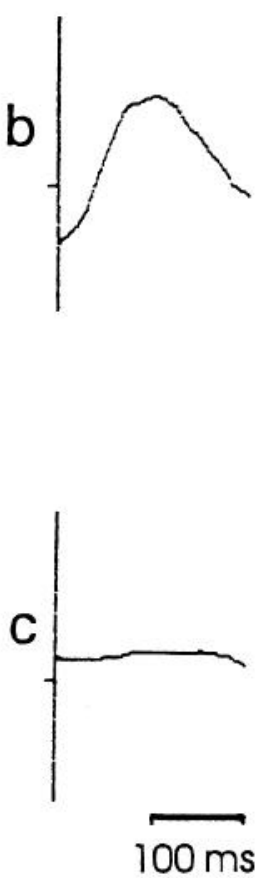

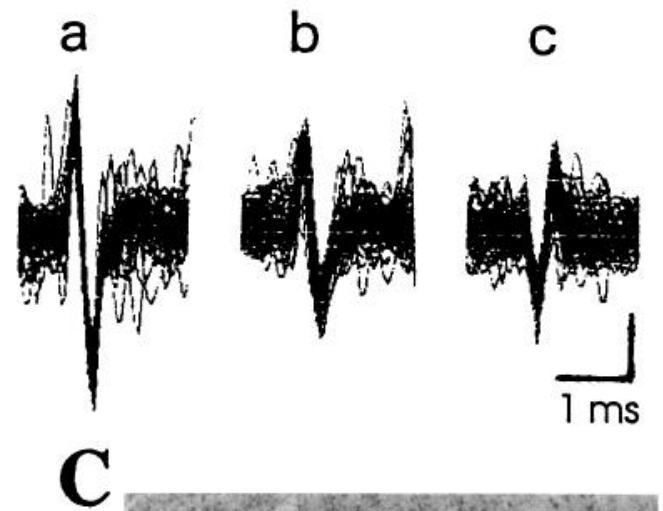

B

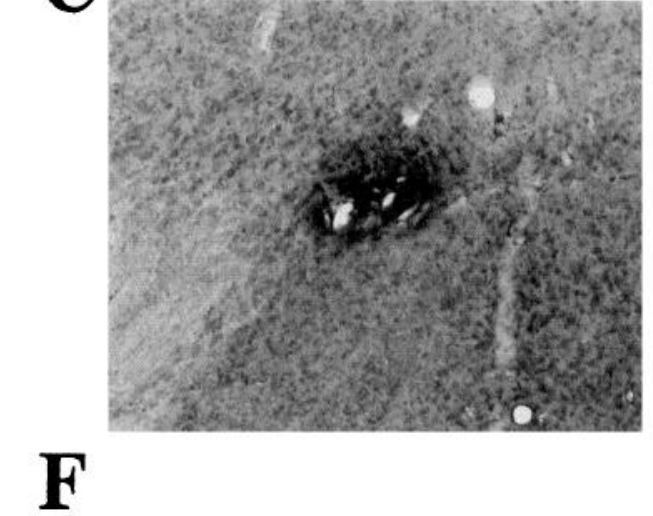

crosscorrelogram
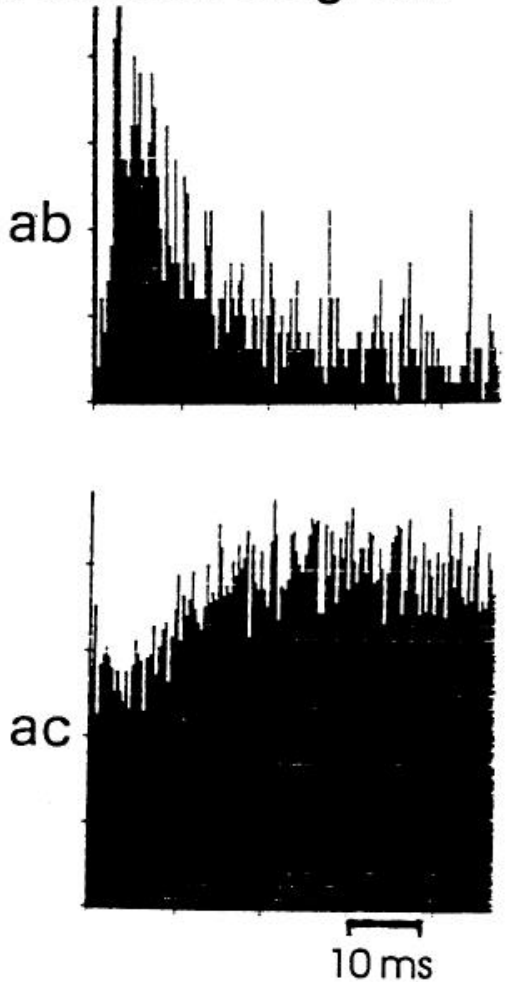

Figure 4. Separation of single unit spikes from unstable noisy recording. A, Samples of electroencephalographic activity of the hippocampus (Hipp, top trace) and simultaneous unit discharge in SUM (bottom trace) after tail pinch. B, Superimposed extracellular potentials separated by the clustering algorithm ("candidate" spikes). $C$, Location of the tip of the recording electrode in the SUM. $D$, Autocorrelograms of each separated "candidate" spike. $E$, Averages of segments of hippocampal EEG triggered by the three "candidate" spikes. $F$, Crosscorrelogram between different pairs of "candidate" spikes. Calibration: $A, 0.5 \mathrm{mV}$ (Hipp), $100 \mu \mathrm{V}(S U M) ; B, 100 \mu \mathrm{V}$. 
A

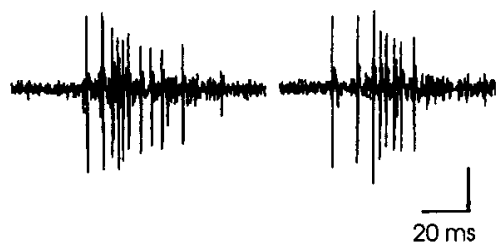

B

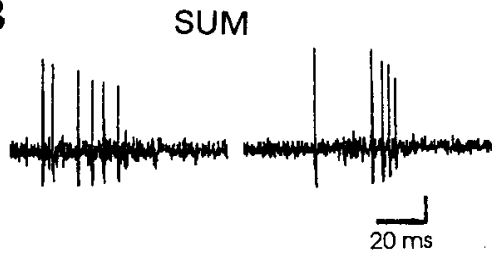

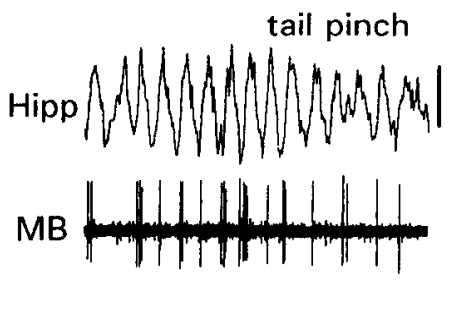

tail pinch

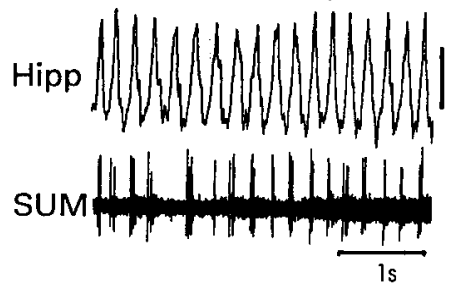

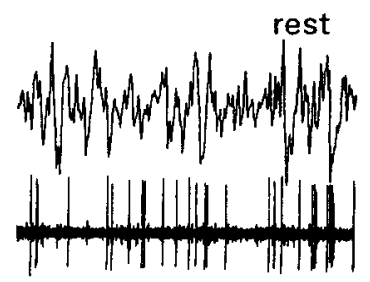

Figure 5. Burst discharge ("complex spikes") of an MB $(A)$ and an SUM $(B)$ neuron (traces on left) and their relationship to hippocampal field activity (middle and right). Note that burst discharge increases during theta episodes. Calibration: $100 \mu \mathrm{V}$ (traces on the left), $0.5 \mathrm{mV}$ (middle and right).

segmented by highly regular periods of silence (Figs. 2-4). Clearly distinctive from these regularly segmented bursts, 11 cells (six in SUM, five in MB) exhibited a unique pattern of bursting activity reminiscent of the complex spikes recorded in the hippocampus (Ranck, 1973).

Figure 5 shows two examples of these bursts consisting of $3-$ 10 spikes separated by very short interspike intervals $(<5-10$ $\mathrm{msec}$ ). Both the amplitude of spikes and the length of intervals between them showed characteristic changes during each burst. The amplitude of the first or the first couple of action potentials was the same as single isolated spikes of the cell. In the complex spike mode, these initial spikes, however, were followed by a barrage of action potentials of lower amplitude and shorter interspike intervals. Toward the end of the bursts, the spike amplitude continued to decrease and the interspike intervals progressively increased. These general features were common for most complex spikes, although there were significant variations among cells as well as between bursts generated by any one cell.

A high signal to noise ratio allowed for a more detailed analysis of nine cells with complex spikes, that is, to test whether they were generated by a group of neurons or by a single cell. The spikes in most of these recordings were clustered in such a way that the large action potentials at the beginning of each complex spike and the small spikes that followed formed two separate groups (Fig. 6A). The autocorrelograms calculated separately for large and small spikes as well as the cross-correlogram describing the relationship between the two groups contained empty bins between 0 and $3 \mathrm{msec}$ indicating that all action potentials were indeed generated by a single cell (Fig. $6 B$ ). Furthermore, the conspicuous asymmetry of the cross-correlogram shows that small spikes always followed the large ones, and not vice versa (Fig. $6 C$ ). Finally, both spike trains were highly correlated with hippocampal theta activity (Fig. 6D). As depicted in Figure $6 D$, these cells (large spikes and at a short delay the small spikes) discharged at the positive phase of CAl theta.

Complex spikes occurred spontaneously during both resting conditions and following tail pinch, more frequently, however, during theta (Figs. 3, 5).
Comparison of coherences between $S U M / M B$ units and the two hippocampal theta generators

The coherences between SUM/MB unit activity and the two hippocampal EEG rccordings (i.c., in CAl and at the hippocampal fissure; see METHODS) were not significantly different. For 19 units (9 SUM, 4 MB, 6 unidentified) partial coherences were calculated to estimate the extent to which this could be explained by the linear correlation between "CA1" and "dentate" theta rhythms (Fig. 7). In 12 units the coherences between unit firing and either CA 1 or dentate theta dropped to zero when allowance was made for the other hippocampal recording (Fig. $7 A$ ). In the other seven, asymmetrical relationships were found between units and the two hippocampal theta generators. The coherence between six units and "CA1" theta remained significant after removal of that part common with "dentate" theta rhythm (Fig. 7B). On the other hand, the demonstration of no significant partial coherence between these six units and "dentate" theta indicated that the coherences between the activity of these units and dentate theta could be predicted from variations in the "CA1" EEG. Finally, one SUM cell showed an asymmetrical relationship but in the opposite direction; that is, the SUM-"dentate" coherence was not completely eliminated by partialization of the "CA1" recording.

As mentioned, partial coherences were examined for four MB cells and for nine SUM cells. Most of the MB units (three out four or $75 \%$ of those tested) showed a stronger correlation with the "CA1" than with "dentate" theta. In contrast, no unequivocal bias was present for SUM cells. Six of the nine SUM units tested $(66 \%)$ were symmetrically related to the two hippocampal EEG recordings as if the two emerged from a single generator. Two of the remaining SUM cells had significant partial coherence with the "CAl" EEG, and one cell with the "dentate" theta EEG.

\section{Discussion}

In the present study, single cells of the SUM and MB were shown to fire rhythmically with the theta rhythm of the hippocampus. 
A a

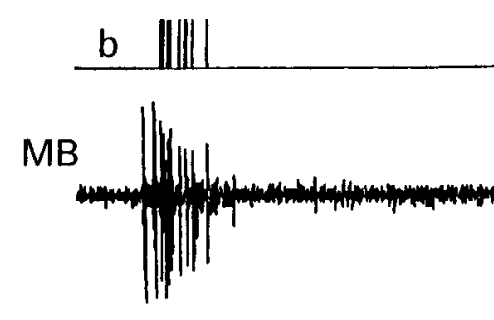

B

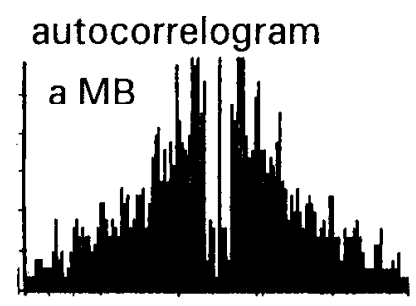

Figure 6. Analysis of "complex spikes" of an MB bursting neuron. $A$, Spikes in each burst (bottom trace) were separated into two classes ( $a$ and $b$ ) according to their amplitude. $B$ and $C$, Autocorrelogram of each class of spikes and their crosscorrelogram calculated with high resolution. $D$, Spike-triggered averages of hippocampal EEG using spikes in classes $a$ (top trace) and $b$ (bottom trace). Calibration: $A, 100 \mu \mathrm{V}$.

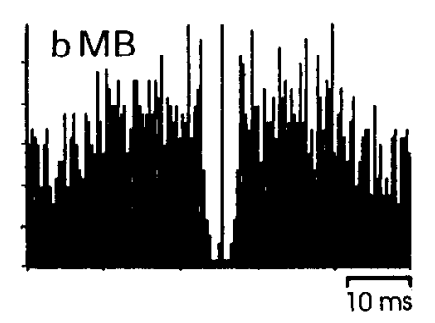

C crosscorrelogram

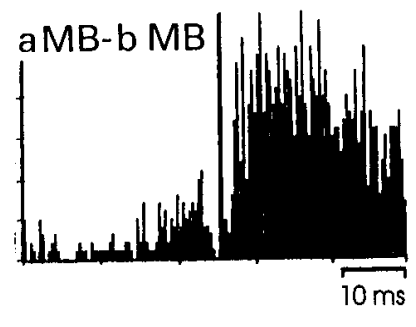

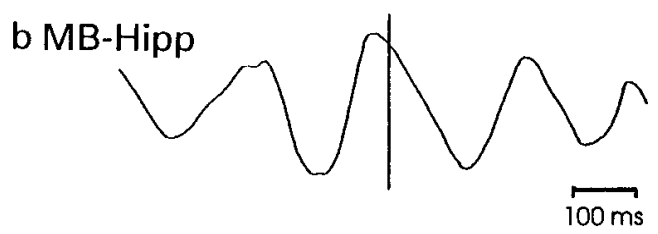

By contrast, no cells in mesencephalic or diencephalic structures outside of the SUM/MB discharged rhythmically with the theta rhythm. SUM and MB cells exhibited similar rates and patterns of discharge. A subset of theta-related cells of SUM and MB discharged in short-duration bursts comparable to the pyramidal complex spikes cells of the hippocampus (Ranck, 1973; Fox and Ranck, 1981; Suzuki and Smith, 1985). In contrast to the hippocampal complex spikes, however, which predominantly exhibit this mode of firing during non-theta states (Ranck, 1973), the burst firing of SUM/MB cells was strongly correlated with the theta rhythm. The proportion of bursting neurons was higher in MB than in SUM. Furthermore, the theta-related cells of $\mathrm{MB}$ showed a stronger correlation with "CAl" than with "dentate" theta, whereas no such asymmetry was found in the relationship between neuronal firing of SUM cells and the two generators of theta in the hippocampus.

\section{Cellular generation of theta rhythmicity in SUM/MB cells}

Based on mean firing rates, theta-related units of the SUM/MB constitute a rather homogeneous cell group. This contrasts with the discharge of theta-related cells in other structures of the brainstem or forebrain. For instance, in the hippocampus theta rhythmic cells (interneurons as well as principal cells) discharge at widely varying rates (Ranck, 1973; Bland et al., 1980; Buzsaki et al., 1983). In like manner, we have recently demonstrated (Kocsis and Vertes, 1992) that the firing rates of theta-related cells of the dorsal raphe nucleus span more than two orders of magnitude (from $0.5-1 \mathrm{~Hz}$ to $70-100 \mathrm{~Hz}$ ).

We found that a large percentage of SUM/MB cells fired rhythmically in bursts. Similar to rhythmically firing cells in other structures (Bland et al., 1980; Buzsaki et al., 1983; Llinas,
1988; Steriade et al., 1993), SUM/MB neurons exhibited two distinct patterns of discharge. Under resting (non-theta) conditions, SUM/MB neurons predominantly fired irregularly spaced single spikes. Paired spikes or bursts were only occasionally observed. During theta, about half of SUM neurons and the majority of MB cells discharged in bursts. The bursts (3-10 spikes of progressively decreasing spike amplitude) were of short duration and synchronous with theta. Similar types of bursting cells ("decrescendo") have been described in the hippocampus (complex spike cells) (Ranck, 1973; Fox and Ranck, 1981; Suzuki and Smith, 1985) and thalamus, and their burst discharge has been shown to be generated intrinsically by neurons possessing various $\mathrm{Ca}^{2+}$ conductances (Schwartzkroin and Slawsky, 1977; Wong and Prince, 1978; Jahnsen and Llinas, 1984).

Llinas and Alonso (1992; Alonso and Llinas, 1992) recently demonstrated that multiple $\mathrm{Ca}^{2+}$ conductances also are present in cells of the MB. Cells of the medial nucleus of MB possess $\mathrm{Ca}^{2+}$ channels that can be activated at or above the resting membrane potential-high and intermediate threshold $\mathrm{CA}^{2+}$ spikes. Llinas and Alonso demonstrated that the activation of the intermediate $\mathrm{Ca}^{2+}$-potential produced sustained repetitive burst firing in medial MB neurons and suggested that this mechanism could produce a theta rhythmicity in these cells. The bursts in the MB slice, however, were slower, lasted longer, and repeated at a significantly lower rates than the theta bursting observed in the present study. Cells showing low-threshold $\mathrm{Ca}^{2+}$ conductances, similar to those underlying rhythmic oscillations in the thalamus (Jahnsen and Llinas, 1984), have also been described in the MB (Alonso and Llinas, 1992; Llinas and Alonso, 1992) and their distribution in the lateral and medial nuclei of MB corresponds to the location of theta-bursting cells of the 
present study. Any of the foregoing $\mathrm{Ca}^{2+}$ conductances could provide the basis for burst firing in $\mathrm{MB}$ neurons. The present data cannot differentiate between these mechanisms or their relative contributions.

An important difference between the burst firing of SUM/MB neurons and CA pyramidal cells is that CA pyramids mainly exhibit complex spike activity during non-theta states, whereas the burst firing in SUM/MB cells predominantly occurs during the theta rhythm (see Figs. 3, 5). In hippocampal pyramidal cells, theta rhythmic input inducing sine-like oscillations of the membrane potential (Fujita and Sato, 1964; Leung and Yim, 1986; Nunez et al., 1987; Soltesz and Deschenes, 1993) triggers rhythmic slow spikes and bursts only if the membrane is depolarized by $>15 \mathrm{mV}$ for sustained periods. This happens rarely in conjunction with theta since CA pyramidal cells are generally suppressed during theta states (Ranck, 1973; Buzsaki et al., 1983; Suzuki and Smith, 1985), although in instances when pyramidal cells fire complex spikes during theta, the discharge is in-phase with the rhythm (Ranck, 1973; Buzsaki et al., 1983). Our demonstration that SUM/MB cells fire in bursts significantly more during theta than non-theta states suggests that, unlike hippocampal pyramidal cells, slow calcium spikes of SUM/MB cells are facilitated during the theta state; that is, the mechanisms underlying burst firing and rhythmic firing in these cells are physiologically coupled.

No detailed information is available regarding the electrophysiological properties (e.g., conductances responsible for burst firing) of SUM neurons. The present findings that MB and SUM neurons exhibit similar firing characteristics suggest common electrophysiological properties. There are, however, more nonbursting neurons in the SUM than in the MB. Nonbursting SUM neurons fire at approximately the same rates as the bursting cells, and like the bursting cells their discharge is synchronized with the theta rhythm.

\section{The possible origin of theta rhythmicity of $S U M / M B$ units}

Hippocampal theta field potentials are produced by multiple dipoles along the soma-dendritic surface of the orderly placed principal cells of the CA and DG (Buzsaki et al., 1986; Brankack et al., 1993). The two largest current sinks are generated by excitatory afferents: (1) from the lateral entorhinal cortex to the stratum lacunosum-moleculare, and (2) from the MS/DBv to the stratum oriens (Buzsaki et al., 1986; Brankack et al., 1993). These sets of afferents are responsible for the two power maxima of theta, one at the hippocampal fissure and the other at the CA1 region, basically corresponding to the two theta generators described in earlier studies (Winson, 1974; Bland et al., 1975). Although an intact MS/DBv is critical for both generators, the rhythmic activation of each is mediated by separate afferents. As a consequence, fine variations of the oscillating dipoles will reflect the influence of different structures (i.e., MS/DBv or lateral entorhinal cortex) despite the fact that there is normally a high coherence between CAl and DG recordings. It has recently been demonstrated (Kocsis et al., 1993a) by partialization of the coherence between potentials at CA1 and DG, with the use of a third theta signal (e.g., from the contralateral side of the hippocampus), that the two generators can be effectively separated.

The present results, using partial coherence analysis, provide evidence that the theta-related discharge of MB but not SUM units is driven by descending projections from the hippocampal formation. Our findings are consistent with the differential an-

\section{A SUM neuron}

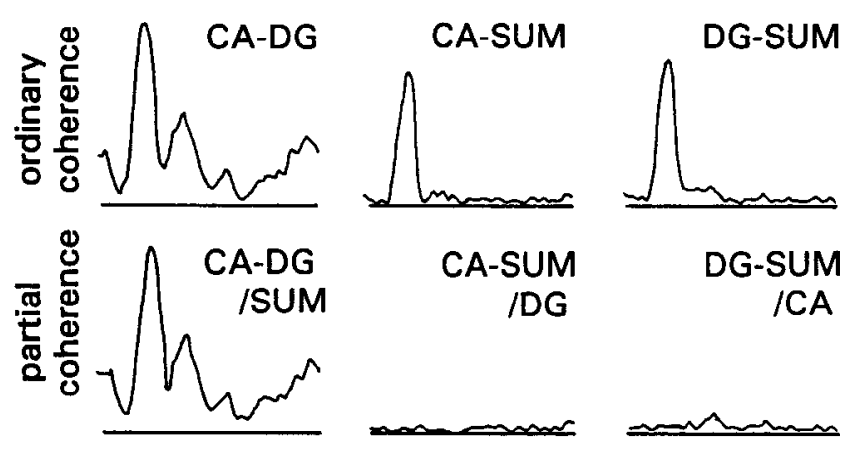

\section{B MB neuron}

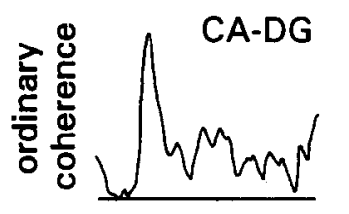

CA-MB

DG-MB
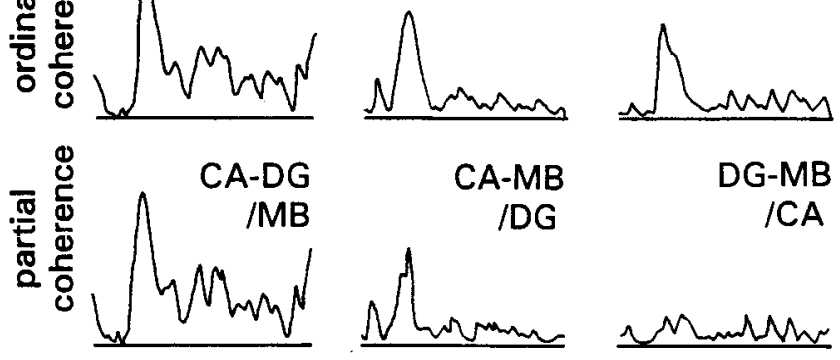

CA-MB

/DG

DG-MB

ICA

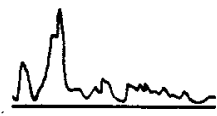

NandMr

\section{frequency $0-15 \mathrm{~Hz}$}

Figure 7. Partial coherence analysis of the discharge of an SUM $(A)$ and an $\mathrm{MB}$ neuron $(B)$ and two simultaneous hippocampal recordings. Ordinary and partial coherences between the two hippocampal EEGs are shown in each row on the left. In the middle and right traces, the coherences between the unit discharge and the hippocampal EEG recorded by the more superficial and the deep electrodes are illustrated, respectively.

atomical connections of the MB, as compared to the SUM, with the hippocampus. For example, the $\mathrm{MB}$ is a major target of hippocampus efferents, whereas the SUM receives few fibers from the hippocampus but is the source of strong projections to specific regions of the hippocampus. The massive hippocampal projection to the MB originates from the subiculum (Swanson and Cowan, 1975, 1977; Allen and Hopkins, 1989)-a site of relatively high-amplitude theta field potentials, about twice that of the CAl region (Buzsaki, 1985; Buzsaki et al, 1986). There is only one subicular theta generator, and it is of the CAl type; that is, its maxima is at the basal dendritic layer (stratum oriens) and is generated by septal input. With the assumption, then, that the discharge of subicular projection cells directly reflects variations of the local field potential, a significantly greater coherence would be expected between the MB (the target of subicular efferents) and the subicular/CAl theta generator than between the MB and the dentate generator. This is what we observed, that is, significant partial coherence between MB cells and CA field potentials, indicating that theta rhythmicity of $\mathrm{MB}$ cells is of hippocampal origin.

There was no such asymmetry in the relationship between SUM unit discharge and the two hippocampal theta generators. The coherence between SUM and one of the hippocampal fields 
could be accounted for hy coherence with the other. The lack of significant partial coherence between SUM and CA1 is consistent with anatomical data showing that the SUM does not receive direct projections from the hippocampus (Hayakawa et al., 1993). The SUM, on the other hand, projects strongly to the hippocampus, particularly to the granule cell layer of DG as well as to the CA2/CA3a area of the dorsal hippocampus (Wyss et al., 1979; Haglund et al., 1984; Saper, 1985; Vertes, 1992; Magloczky et al., in press). This relatively selective SUM projection to the DG did not, as might be expected, give rise to a significant partial coherence between the SUM and DG even though, as indicated here and previously (Kirk and McNaughton, 1991), the SUM contains a very high proportion of theta-related cells.

Several not nccessarily cxclusive possibilitics could account for the lack of significant partial coherence between SUM and DG. First, there is no evidence that a theta-synchronous input from the SUM to the hippocampus produces synchronous field activity in the hippocampus. In this regard, although electron microscopic data indicate that SUM fibers form excitatory synapses on the dentate granule cells (Dent et al., 1983; Magloczky et al., in press) electrical stimulation of the SUM apparently does not produce evoked potentials in the hippocampus (Segal, 1979; Dahl and Winson, 1986; Mizumori et al., 1989). SUMelicited activation of DG cells (Dahl and Winson, 1986; Mizumori et al., 1989; Carre and Harley, 1991) is thought to be brought about a by disinhibition of granule cells rather than by their direct excitation (Mizumori et al., 1991). If the synchronized SUM input terminates on interneurons, the undefined random orientation of these cells would oppose the generation of a strong field activity. The "patch-like" distribution of the SUM fibers (i.e., discontinuous bundles of fibers selectively innervating circumscribed populations of granule cells) (Haglund et al., 1984; Vertes, 1992) would also weaken evoked potentials. Second, even if a rhythmic SUM-driven field potential is generated in the DG, it may be weak compared with other "dentate" field activities. The deep electrode of the present study was placed at or below the hippocampal fissure and as such was probably mainly influenced by field activity evoked by the massive input from the lateral entorhinal cortex. In like manner, other theta generators driven by afferents from the medial entorhinal cortex or by commissural input could have been stronger and closer to the recording electrode than generators possibly driven by SUM afferents. Third, the coherence shown here between SUM and DG may rely more on connections between the SUM and septum (Vertes, 1988, 1992) than on a direct SUM-DG projection. Accordingly, the rhythmic SUM influence would reach the DG through a multisynaptic pathway, that is, complex circuits with nonlinearities and feedback loops. If this were the case, the influence of the SUM on the DG would not be expected to be selective, that is, not significantly different than the influence of the SUM on CAI.

\section{The role of theta rhythmic discharge of SUM and $M B$ neurons}

The well-recognized interconnections of the SUM/MB with forebrain structures displaying theta rhythmicity, particularly the septum and hippocampus, indicate a significant interplay between the SUM/MB and the forebrain in the control or modulation of synchronous activity within the hippocampus.

There are several routes by which the SUM/MB may influence theta related processes in the hippocampus. The SUM not only projects densely to the DG but also to several structures with pronounced input to the hippocampus including the nucleus reuniens of the thalamus, the medial and lateral septum and the entorhinal cortex (Vertes, 1992). The MB receives strong projections from the hippocampus (Swanson and Cowan, 1975, 1977; Allen and Hopkins, 1989), and in turn can influence hippocampal activity through a return circuit involving the anterior thalamus $\rightarrow$ cingulate cortex $\rightarrow$ entorhinal cortex $\rightarrow$ hippocampus (Papez, 1937)

The present results as well as previous findings (Kirk and McNaughton, 1991; Bland et al., 1993; Kocsis et al., 1993b) showing that a large majority of SUM/MB neurons fire rhythmically with theta suggests that (1) the various targets of the SUM/MB fibers receive a theta rhythmical input, and (2) that this rhythmical input may be critical not only for the control of theta activity but also for other processes linked to theta rhythmicity.

SUM to septum projection. We initially proposed (Vertes, 1986) that the SUM was involved in the generation of the hippocampal theta on the following basis. It is well established that hippocampal theta is driven by pacemaking cells of the MS/ DBv (Petsche et al., 1962, 1965; Stumpf et al., 1962) and that these septal cells are in turn activated by input arising from the brainstem reticular formation (Green and Arduini, 1954). We showed that a subset of neurons in the nucleus pontis oralis (RPO) is selectively active during theta associated behaviors (Vertes, 1979) and that RPO was the most effective brainstem site for elicitation of theta with electrical stimulation in the anesthetized rat (Vertes, 1981). The RPO, however, sends few direct projections to the septum (Vertes, 1988; Vertes and Martin, 1988), indicating that the synchronizing effects of RPO on the MS/DBv are mediated by an intervening nucleus (or nuclei). We proposed (Vertes, 1986) that this intervening nucleus was the SUM based on anatomical links between the RPO and SUM (Vertes and Martin, 1988) and in turn the SUM and MS/DBv (Vertes, 1988, 1992) and the fact that electrical stimulation in the SUM area generated hippocampal theta (Vertes, 1981). The anatomical location of SUM cells projecting to the septum (i.e., mediolateral and lateral parts of SUM) corresponds to the distribution of theta related neurons of the present study (see Fig. 1).

Until recently, the MS/DBv was considered the sole pacemaker involved in conversion of a nonrhythmical activity into theta rhythmical firing (Bland, 1986, Bland and Colom, 1993). Our results, as well as recent findings of others (Kirk and McNaughton, 1991; Bland et al., 1993), suggest that the long-standing assumptions that the septum is the primary (or sole) source of a rhythmical input to the hippocampus and/or that afferents to the septum are entirely nonrhythmical, may no longer be tenable. For instance, Kirk and McNaughton (1991) not only demonstrated that SUM cells (multiunits) fire rhythmically with theta, but further showed that septal injections of procaine that abolished hippocampal theta did not alter synchronous firing of SUM neurons. This indicates that SUM cells can fire rhythmically independent of the septum or hippocampus. Kirk and McNaughton (1991) suggested that the SUM transduces the intensity of brainstem activation into theta rhythmicity, and that theta frequency is encoded in the SUM rather than in the septum.

$S U M$ to $D G$ projection. The DG receives rhythmical input from the SUM via direct projections from the SUM to DG. SUM fibers distribute to a very restricted zone of the DG-the 
outer half of the granule layer and the immediately adjacent molecular layer (Wyss et al., 1979; Dent et al., 1983; Haglund et al., 1984; Vertes, 1992). These afferents are in a position to exert a strong influence on granule cells. It is worth noting that of all the rhythmical inputs to the hippocampus, the SUM is the only one with such an exclusive projection to the DG. Both electrical (Dahl and Winson, 1986; Mizumori et al., 1989) and chemical (Carre and Harley, 1991) stimulation of the SUM have been shown to potentiate the effects of perforant path stimulation at the DG. The present demonstration of theta rhythmically firing cells in SUM would suggest that an SUM facilitation of DG activity would be produced in a rhythmic manner synchronous with theta. Buzsaki (1989; Buzsaki and Czeh, 1992) proposed that the physiological function of theta discharge of granule cells is to tetanize CA3 pyramidal neurons during exploratory behaviors thereby producing a reorganization of the functional connectivity of the CA3 network. The SUM projection to DG may enhance this function.

\section{References}

Allen GV, Hopkins DA (1989) Mammillary body in the rat: topography and synaptology of projections from the subicular complex, prefrontal complex, and midbrain tegmentum. J Comp Neurol 286: 311-336.

Alonso A, Llinas RR (1992) Electrophysiology of the mammillary complex in vitro. II. Medial mammillary neurons. J Neurophysiol 68: $1321-1331$

Bland $\mathrm{BH}$ (1986) The physiology and pharmacology of hippocampal formation theta rhythms. Prog Neurobiol 26:1-54.

Bland BH, Colom LV (1993) Extrinsic and intrinsic properties underlying oscillation and synchrony in limbic cortex. Prog Neurobiol 41:157-208.

Bland BH, Andersen P, Ganes T (1975) Two generators of hippocampal theta activity in rabbits. Brain Res $94: 199-218$.

Bland BH, Andersen P, Ganes T, Sveen O (1980) Automated analysis of rhythmicity of physiologically identified hippocampal formation neurons. Exp Brain Res 38:205-219.

Bland BH, Oddie SD, Dickson CT, Trepel C (1993) Discharge patterns of posterior-supramammillary hypothalamic cells in relation to hippocampal theta field activity. Soc Neurosci Abstr 19:355.

Brankack J, Stewart M, Fox SE (1993) Current source density analysis of the hippocampal theta rhythm-associated sustained potentials and candidate synaptic generators. Brain Res 615:310-327.

Buzsaki G (1985) Electroanatomy of the hippocampal rhythmic slow activity (RSA) in the behaving rat. In: Electrical activity of the archicortex (Buzsaki $\mathrm{G}$, Vanderwolf $\mathrm{CH}$, eds), pp 143-164. Budapest: Akademia Kiado.

Buzsaki G (1989) Two-stage model of memory trace formation: a role for "noisy" brain states. Neuroscience 31:551-570.

Buzsaki G, Czeh G (1992) Physiological function of granule cells: a hypothesis. In: Epilepsy research, Suppl 7, The dentate gyrus and its role in seizures (Ribak CE, Gall CM, Mody I, eds), pp 281-290. New York: Elsevier.

Buzsaki G, Leung LS, Vanderwolf $\mathrm{CH}$ (1983) Cellular bases of hippocampal EEG in the behaving rat. Brain Res Rev 6:139-171.

Buzsaki G, Czopf J, Kondakor I, Kellenyi L (1986) Laminar distribution of hippocampal rhythmic slow activity (RSA) in the behaving rat: current-source density analysis. Effects of urethane and atropine. Brain Res 365:125-137.

Carre GP, Harley CW (1991) Population spike facilitation in the dentate gyrus following glutamate to the lateral supramammillary nucleus. Brain Res 568:307-310.

Christakos CN, Cohen MI, Barnhardt R, Shaw CF (1991) Fast rhythms in phrenic motoneuron and nerve discharges. J Neurophysiol 66:674687.

Dahl D, Winson J (1986) Influence of neurons of the parafascicular region on neuronal transmission from perforant pathway through dentate gyrus. Brain Res 377:391-396.

Dembowsky K, Kocsis B, Neus M, Czachurski J, Seller H (1988) Cluster analysis of EPSPs of the on-going synaptic activity in sympathetic preganglionic neurons in the cat. Pfluegers Arch 412:R73.
Dent JA, Galvin NJ, Stanfield BB, Cowan WM (1983) The mode of tcrmination of the hypothalamic projection to the dentate gyrus: an EM autoradiographic study. Brain Res 258:1-10.

Fox SE, Ranck JB (1981) Electrophysiological characteristics of hippocampal complex-spike cells and theta cells. Exp Brain Res 41:399410.

Fox SE, Ranck JB (1986) Hippocampal theta rhythm and the firing of neurons in walking and urethane anesthetized rats. Exp Brain Res 62:495-508.

Fujita Y, Sato T (1964) Intracellular records from hippocampal pyramidal cells in rabbit during theta rhythm activity. J Neurophysiol 27:1011-1026.

Gebber GL, Barman SM, Kocsis B (1990) Coherence of medullary unit activity and sympathetic nerve discharge. Am J Physiol 259: R561-R571.

Gersch W, Goddard GV (1970) Epileptic focus location: spectral analysis method. Science 169:701-702.

Gonzalo-Ruiz A, Alonso A, Sanz JM, Llinas RR (1992) Afferent projections to the mammillary complex of the rat, with special reference to those from surrounding hypothalamic regions. J Comp Neurol 321: 277-299.

Green JD, Arduini A (1954) Hippocampal electrical activity in arousal. J Neurophysiol 17:533-557.

Greenstein YJ, Pavlides C, Winson J (1988) Long-term potentiation in the dentate gyrus is preferentially induced at theta rhythm periodicity. Brain Res 438:331-334.

Haglund L, Swanson SW, Kohler C (1984) The projection of the supramammillary nucleus to the hippocampal formation: an immunohistochemical and anterograde transport study with the lectin PHA-L in the rat. J Comp Neurol 229:171-185.

Hartigan JA (1975) Clustering algorithms. New York: Wiley.

Hayakawa T, Ito H, Zyo K (1993) Neuroanatomical study of afferent projections to the supramammillary nucleus of the rat. Anat Embryol (Berl) 188:139-148.

Jahnsen H, Llinas R (1984) Electrophysiological properties of guineapig thalamic neurones: an in vitro study. J Physiol (Lond) 349:205226

Jenkins GM, Watts DG (1968) Spectral analysis and its applications. San Francisco: Holden-Day.

Jung R, Kornmuller A (1938) Eine Methodik der Ableitung lokalisierter Potential-Schwankungen aus subkortikalen Hirngenieten. Arch Psychiatr Nervenkr 109:1-30.

Kirk IJ, McNaughton N (1991) Supramammillary cell firing and hippocampal rhythmical slow activity. Neuroreport 2:723-725.

Kocsis B, Vertes RP (1992) Dorsal raphe neurons: synchronous discharge with theta rhythm of the hippocampus in the freely moving rat. J Neurophysiol 68:1463-1467.

Kocsis B, Dembowsky K, Gebber GL (1989) A modified K-means clustering algorithm for classification of neurophysiological waveforms (slow waves). Proc IEEE Eng Med Biol Soc 1 1:1247-1249.

Kocsis B, Gebber GL, Barman SM, Kenney MJ (1990) Relationships between activity of sympathetic nerve pairs: phase and coherence. Am J Physiol 259:R549-R560.

Kocsis B, Thinschmidt JS, Kinney GG, Vertes RP (1993a) Separation of two hippocampal theta rhythm generators by means of partial coherence analysis. Proc Am EEG Soc Annu Meeting, Electroencephalogr Clin Neurophysiol, in press.

Kocsis B, Vertes RP, Thinschmidt JS (1993b) Discharge properties of neurons of the supramammillary nucleus and mammillary body: relationship to hippocampal theta rhythm. Soc Neurosci Abstr 19: 1442.

Larson J, Lynch G (1986) Induction of synaptic potentiation in hippocampus by patterned stimulation involves two events. Science 232: 985-988.

Leung LS, Buzsaki G (1983) Spectral analysis of hippocampal EEG. Electroencephalogr Clin Neurophysiol 56:668-671.

Leung LS, Yim CY (1986) Intracellular theta in hippocampal pyramidal cells in the urethane anesthetized rat. Brain Res 367:323-327.

Llinas RR (1988) The intrinsic clcctrophysiological properties of mammalian neurons: insight into central nervous system function. Science 242:1654-1664.

Llinas RR, Alonso A (1992) Electrophysiology of the mammillary complex in vitro. I. Tuberomammillary and lateral mammillary neurons. J Neurophysiol 68:1307-1320.

Lopes da Silva FH, Vos JE, Mooibroek J, Van Rotterdam A (1980) Relative contributions of intracortical and thalamo-cortical processes 
in the generation of alpha rhythms, revealed by partial coherence analysis. Electroencephalogr Clin Neurophysiol 50:449-456.

MacLean P (1952) Some psychiatric implications of physiological studies on frontotemporal portion of limbic system (visceral brain). Electroencephalogr Clin Neurophysiol 4:407-418.

Magloczky Z, Acsady L, Freund TF (in press) Principal cells are the postsynaptic targets of supramammillary afferents in the hippocampus in the rat. Hippocampus, in press.

Mizumori SJY, McNaughton BL, Barnes CA (1989) A comparison of supramammillary and medial septal influences on hippocampal field potentials and single-unit activity. J Neurophysiol 61:15-31.

Nunez A, Garcia-Austt E, Buno W (1987) Intracellular $\theta$-rhythm generation in identified hippocampal pyramids. Brain Res 416:289-300.

Nunez A, de Andres I, Garcia-Austt E (1991) Relationship of nucleus reticularis pontis caudalis neuronal discharge with sensory and carbachol evoked hippocampal theta rhythm. Exp Brain Res 87:303308.

Oddie SD, Bland BH, Colom LV, Vertes RP (in press) The midline posterior hypothalamic region comprises a critical part of the ascending brainstem hippocampal synchronizing pathway. Hippocampus, in press.

Papez JW (1937) A proposed mechanism of emotion. Arch Neurol Psychiatry 38:725-743.

Pavlides C, Greenstein YJ, Grudman M, Winson J (1988) Long-term potentiation in the dentate gyrus is induced preferentially on the positive phase of theta-rhythm. Brain Res 439:383-387.

Petsche H, Stumpf G, Gogolak G (1962) The significance of the rabbit septum as a relay station between the midbrain and the hippocampus. I. The control of hippocampus arousal activity by the septum cells. Electroencephalogr Clin Neurophysiol 14:202-211.

Petsche H, Gogolak G, Van Zwieten PA (1965) Rhythmicity of septal cell discharges at various levels of reticular excitation. Electroencephalogr Clin Neurophysiol 19:25-33.

Ranck JB (1973) Studies on single neurons in dorsal hippocampal formation and septum in unrestrained rats. I. Behavioral correlates and firing repertoires. Exp Neurol 41:463-531.

Room P, Groenewegen HJ (1986) Connections of the parahippocampal cortex in the cat. II. Subcortical afferents. J Comp Neurol 251: $451-473$.

Rose GM, Dunwiddie TV (1986) Induction of hippocampal long-term potentiation using physiologically patterned stimulation. Neurosci Lett 69:244-248.

Salganicoff M, Sarna M, Sax L, Gerstein GL (1988) Unsupervised waveform classification for multiunit recordings: a real-time softwarebased system. I. Algorithms and implementation. J Neurosci Methods $25: 181-187$

Saper CB (1985) Organization of cerebral cortical afferent system in the rat. II. Hypothalamocortical projections. J Comp Neurol 237:2146.

Schwartzkroin PA, Slawsky M (1977) Probable calcium spikes in hippocampal neurons. Brain Res 135:157-161.

Segal M (1979) A potent inhibitory monosynaptic hypothalamo-hippocampal connection. Brain Res 162:137-141.

Shepard PD, Mihailoff GA, Germna DC (1988) Anatomical and electrophysiological characterization of presumed dopamine-containing neurons within the supramammillary region of the rat. Brain Res Bull 20:307-314

Shibata (1988) A direct projection from the entorhinal cortex to the mammillary nuclei in the rat. Neurosci Lett 90:6-10.

Soltesz I, Deschenes M (1993) Low- and high-frequency membrane potential oscillations during theta activity in $\mathrm{CA} 1$ and $\mathrm{CA} 3$ pyramidal neurons of the rat hippocampus under ketamine-xylazine anesthesia. J Neurophysiol 70:97-116.

Staubli U, Lynch G (1987) Stable long-term hippocampal potentiation elicited by 'theta' pattern stimulation. Brain Res 435:227-234.

Steriade M, McCormick DA, Sejnowski TJ (1993) Thalamocortical oscillations in the sleeping and aroused brain. Science 262:679-685.

Stewart M, Fox SE (1990) Firing relations of lateral septal neurons to the hippocampal theta rhythm in urethane anesthetized rats. Exp Brain Res 79:92-96.

Stumpf C, Petsche H, Gogolak G (1962) The significance of the rabbit septum as a relay station between the midbrain and the hippocampus. II. The differential influence of drugs upon the septal cell firing pattern and the hippocampus theta activity. Electroencephalogr Clin Neurophysiol 14:212-219.

Suzuki SS, Smith GK (1985) Burst characteristics of hippocampal complex spike cells in the awake rat. Exp Neurol 89:90-95.

Swanson LW, Cowan WM (1975) Hippocampo-hypothalamic connections: origin in subicular cortex, not Ammon's horn. Science 189: 303-304.

Swanson LW, Cowan WM (1977) An autoradiographic study of the organization of the efferent connections of the hippocampal formation in the rat. $\mathbf{J}$ Comp Neurol 172:49-84.

Swanson LW, Cowan WM (1979) The connections of the septal region in the rat. J Comp Neurol 186:621-656.

Vanderwolf CH (1969) Hippocampal electrical activity and voluntary movement in the rat. Electroencephalogr Clin Neurophysiol 26:407418.

Vertes RP (1979) Brain stem gigantocellular neurons: patterns of activity during behavior and sleep in the freely moving rat. J Neurophysiol 42:214-228.

Vertes RP (1981) An analysis of ascending brain stem systems involved in hippocampal synchronization and desynchronization. $\mathrm{J}$ Neurophysiol 46:1140-1159.

Vertes RP (1984) A lectin horseradish peroxidase study of the origin of ascending fibers in the medial forebrain bundle of the rat. The upper brainstem. Neuroscience 11:669-690.

Vertes RP (1986) Brainstem modulation of the hippocampus. Anatomy, physiology and significance. In: The hippocampus, Vol 4 (Isaacson RL, Pribram KH, eds), pp 41-75, New York: Plenum.

Vertes RP (1988) Brainstem afferents to the basal forebrain in the rat. Neuroscience 24:907-935.

Vertes RP (1992) PHA-L analysis of projections from the supramammillary nucleus in the rat. J Comp Neurol 326:595-622.

Vertes RP, Martin GF (1988) Autoradiographic analysis of ascending projections from the pontine and mesencephalic reticular formation and the median raphe nucleus in the rat. J Comp Neurol 275:511541 .

Winson J (1972) Interspecies differences in the occurrence of theta Behav Biol 7:479-487.

Winson J (1974) Patterns of hippocampal theta rhythm in the freely moving rat. Electroencephalogr Clin Neurophysiol 36:291-301.

Wong RKS, Prince DA (1978) Participation of calcium spikes during intrinsic burst firing in hippocampal neurons. Brain Res 159:385390.

Wyss JM, Swanson LW, Cowan WM (1979) Evidence for an input to the molecular layer and the stratum granulosum of the dentate gyrus from the supramammillary region of the hypothalamus. Anat Embryol (Berl) 156:165-176. 